\title{
The Role of Pharmacist in Managing Hypertension in the Community: Findings from a Community Based Study
}

\author{
Tan Ching Siang ${ }^{1, *}$, Mohamed Azmi Ahmad Hassali ${ }^{2}$, Neoh Chin Fen ${ }^{3}$ \\ ${ }^{1}$ Dean, School of Pharmacy, KPJ University College, Nilai, Negeri Sembilan, MALAYSIA \\ ${ }^{2}$ School of Pharmaceutical Sciences, Universiti Sains Malaysia, Penang, MALAYSIA. \\ ${ }^{3}$ Faculty of Pharmacy, Universiti Teknologi MARA, Puncak Alam, MALAYSIA.
}

\begin{abstract}
Introduction: Pharmacist led health education programs have been initiated to improve Blood Pressure (BP) control in the community and patients' knowledge on a disease and therapy, lifestyle changes and medication adherence among hypertensive patients. This study aimed to evaluate pharmacist led health education program among hypertensive patients, in local community-based setting, by assessing the changes in blood pressure control, beliefs about medicine, antihypertensive medications adherence and quality use of medication. Methods: This study was prospective convenient sampling, with communitybased health education study involving 45 participants at the Community Service Hall in Bukit Mertajam, Penang, Malaysia. Participants received health education program over 4 months period: Introduction of hypertension, pharmacological management of hypertension, quality use of medication and diet and lifestyle changes. Outcomes included the changes Blood Pressure (BP) level, Malaysian Medication Adherence Assessment (MALMAS), Beliefs about Medicines Questionnaire (BMQ) and Quality Use of Medication (QUM). Results: Both systolic BP $(146.6 \pm 11.1 \mathrm{mmHg}, P<0.001)$ and diastolic BP $(87.6 \pm 9.6 \mathrm{mmHg}, P=0.002)$ decreased significantly after the 2-months intervention. Systolic BP was successfully reduced significantly to $140.1 \pm 10.7 \mathrm{~mm} \mathrm{Hg}$ $(P<0.001)$ after the 4-months intervention. Medication adherents increased significantly from baseline $(29.3 \%)$ to 2 -months interventions $(58.5 \%, P=0.005)$ and 4 -months interventions $(70.7 \%, P<0.001)$. Significant improvement was also noticed in $\mathrm{BMO}$ and QUM. Conclusion: Pharmacist led health education program has significantly desirable effects on improvement of blood pressure, better beliefs about medicine, improvement of medication adherence and better rational use of medication
\end{abstract}

Key words: Pharmacist led education program, Hypertension, Medication adherence, Beliefs about medicine, Quality use of medication.

\section{INTRODUCTION}

Hypertension is a serious chronic disease in worldwide, with an estimated 1 billion people globally afflicted with this disease. ${ }^{1,2}$ According to the Joint National Committee 7 (JNC 7), hypertension is defined as physician office systolic BP level of $\geq 140$ millimetres of mercury $(\mathrm{mmHg})$ and diastolic BP of $\geq 90 \mathrm{mmHg}^{3}$ In Malaysia, about $30.3 \%$ of adults of 18 years and above has hypertension ${ }^{4}$ and only $26.6 \%$ of hypertensive patients had a blood pressure of $\leq 140 / 90 \mathrm{mmHg} .{ }^{5}$ Uncontrolled hypertension can lead to significant morbidity and mortality, accounting for at least 45\% of deaths due to heart disease and 51\% of deaths due to stroke. ${ }^{1,6}$ However, clinical research demonstrated that heart failure, strokes and myocardial infarction can be reduced by $50 \%, 35-40 \%$ and $20-25 \%$, respectively, if blood pressure is being controlled. ${ }^{3}$ Evidence showed that a $5-\mathrm{mmHg}$ reduction of Systolic Blood Pressure (SBP)
Submission Date: 18-02-2019; Revision Date: 27-03-2019; Accepted Date: 09-05-2019

DOI: 10.5530/ijper.53.3.88 Correspondence: Dr. Tan Ching Siang, Dean, School of Pharmacy, KPJ University College, 71800 Nilai, Negeri Sembilan, MALAYSIA. Phone: +60 174222526 E-mail: chingsiang9@ hotmail.com

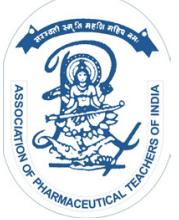

www.ijper.org 
is predicted to eventually reduce $14 \%$ in mortality due to stroke and a $9 \%$ reduction in mortality due to cardiovascular heart disease. ${ }^{7,8}$ Poor adherence to antihypertensive medication is associated with negative clinical outcome of the disease. ${ }^{9}$ Medication adherence among hypertensive patients was reported ranged from 50\% to $70 \% .{ }^{10}$ In Malaysia, only about half $(53.4 \%)$ of the hypertensive patients achieved good medication adherence at the primary care setting. ${ }^{11}$ A recent local study revealed that the reasons of poor medication adherence among hypertensive patients were due to misconception about side effect of antihypertensive medication and lack of knowledge towards hypertension management. ${ }^{12}$ Recently, several health education programs have been initiated to improve blood pressure control in the community ${ }^{13}$ and patients' knowledge on a disease and therapy, ${ }^{14}$ including pharmacist led intervention in lifestyle changes and medication adherence among hypertensive patients. ${ }^{15-17}$ A meta-analysis study showed that pharmacist led intervention was associated with significant reductions in systolic blood pressure [11 studies (2240 patients); $-6.1 \mathrm{mmHg}$ (95\% confidence interval, -3.8 to $-8.4 \mathrm{mmHg}) ; P<0.00001] .{ }^{18}$ In addition, previous studies have demonstrated pharmacist led interventions can rationalise medication use in patients ${ }^{19,20}$ and taking more positive role in patient self-management. ${ }^{16,21}$ The educational tools include health booklets, cartoon pictures and public lecture with animations illustrating video gave a beneficial impact to patient in understanding disease management. ${ }^{22,23}$ In general, health education underpin an important role in the management of hypertensive patients. ${ }^{23}$ Patient education was recognised as key strategic intervention to improve lifestyle changes and medication adherence among hypertensive patients. ${ }^{24-26}$ Literature demonstrated that pharmacist led education program in hypertension management, were come from the western and other Asian countries, with majority of the studies conducted at primary care setting. ${ }^{13,16,23}$

\section{Aim of the Study}

There is a need to evaluate pharmacist led health education program among hypertensive patients, in local community-based setting, by assessing the primary outcome of the changes in blood pressure control, followed by the secondary outcomes of beliefs about medicine, antihypertensive medications adherence and Quality Use of Medication (QUM).

\section{Ethics Approval}

This study was approved by the Joint Ethics Committee of the School of Pharmaceutical Sciences, USM-
Hospital Lam Wah Ee [Reference no: USM-HLWE/ IEC/2014 (0003)]. Written informed consent was obtained from all patients prior to their participation in this study.

\section{METHOD}

\section{Study Design}

This study was a single-centre, prospective convenient sampling, with community-based health education study involving 45 participants at the Community Service Hall, Residential Flat Desa Wawasan in Bukit Mertajam, Penang, Malaysia.

\section{Participants and Intervention}

Patients were recruited among hypertensive patients who stayed at Bukit Mertajam, Penang, Malaysia. Participation was solicited through posters invitation and health awareness booths which were set up at the residential area and multipurpose hall two months prior the health education program. Patients were recruited if they met with the following criteria: age 18 years old and above, prescribed with at least one antihypertensive medication for the past three months, capable to communicate verbally with English or Malay and committed to participate the assigned health education program. Uncontrolled blood pressure (Non-diabetic patients) with systolic blood pressure higher than $140 \mathrm{mmHg}$ or Diastolic Blood Pressure (DBP) higher than $90 \mathrm{mmHg}$, with the average of two measurements taken during enrolment process. Uncontrolled blood pressure (Diabetic patients) with systolic blood pressure higher than $130 \mathrm{mmHg}$ or diastolic blood pressure higher than 80 $\mathrm{mmHg}$, with the average of two measurements taken during enrolment process. Patients were excluded if severe enduring health problems, pregnant, cognitive impairment, or serious chronic diseases with special care needed such as serious heart failure, kidney disease etc.

The recruitment was carried out in March and April 2016. The primary outcome for this pilot study is to reduce blood pressure level $(\mathrm{mmHg})$. Literature suggests that reduction of 5 - $\mathrm{mmHg}$ of systolic blood pressure is significantly associated with a risk reduction of coronary heart disease, stroke and other serious cardiovascular events. ${ }^{27-29}$ Therefore, a $5-\mathrm{mmHg}$ reduction in blood pressure is associated clinically relevant. ${ }^{78}$ This study has adopted a standard deviation of $10-\mathrm{mmHg}$ from previous study. ${ }^{15}$ This study measured the changes of blood pressures and several variables from a single group and compared the before and after intervention. Hence, a sample size of 31 is required to detect the dif- 
ference of $5-\mathrm{mmHg}$ of blood pressure level after the health education program, with a test power of $80 \%$ and two tailed 95\% confidence level. ${ }^{30}$ To account for an estimated $30 \%$ patient dropout rate or loss to followup, the total sample size was adjusted upward from 31 patients to 45 patients. ${ }^{31-33}$

The health education program lasted six months from April 2016 to October 2016, with baseline data collection was done from April to June 2016. The study flowchart is presented in Figure 1. The health education program on hypertension syllabus was developed and designed by several cardiovascular experts, including Professor in Pharmacy Practice and senior clinical pharmacist. The health education program consists of 4 modules: I) Introduction of hypertension; II) Pharmacological Management of hypertension; III) QUM and IV) Non-pharmacological Management of Hypertension - Diet and Lifestyle changes (Table 1). Module I and II were carried out in June 2017; while module III and IV were conducted in August 2017. The health education session was conducted by a pharmacist (Module I-III) and a nutritionist (Module IV) by projecting PowerPoint slide and animation video presentation. Each of the patients was given an educational tool includes cartoon pictures handouts. The duration for each module took about two and half hours. A question and answering session, including individual counselling was allocated after completion of each module.

\section{Outcome Measurements}

The primary outcome was the changes in blood pressure level from baseline to two and four months after the health education program. Other outcomes included the changes in Medication Adherence Assessment (MALMAS), Beliefs about Medicines (BMQ) and QUM. Blood pressure was measured using BP monitoring apparatus (Brand: Omron ${ }^{\circledR}$ with model HEM7080). Patients were requested to be seated for 10 mins before BP measurement. BP was recorded based on the average of three readings.

In this study, the medication adherences among the hypertensive patients were assessed by using the MALMAS. It is an useful and reliable self-administered questionnaire to evaluate the medication adherence of patients with non-communicable diseases. ${ }^{34,35}$ MALMAS consists of one domain with 8 items. MALMAS consists of total score ranged from zero to eight. With the cut-off point of six, patient is classified as adherence (6-8) and non-adherence $(<6)$. MALMAS achieved a significant correlation with the self-reported medication adherence questionnaire and medication refill adherence among hypertensive patients. ${ }^{35,36}$
The beliefs of medication among hypertensive patients were evaluated using the BMQ developed by Horne et al. ${ }^{37,38}$ The BMQ questionnaire consists of 18 questions and can be divided into two parts: specific and general beliefs about medication. The BMQ Specific comprises of five-points Likert scales to evaluate patient's belief towards the necessity of medication (Specific-Necessity) and danger and toxicity of medication (Specific-Concern), harmfulness caused by medication (General-Harm) and pharmacology management by general practitioner (General-Overuse) ${ }^{37}$ The higher score is associated with stronger belief and concern in the concept reflected for each part of assessment. A Necessity-Concerns differential (NCD) was calculated between the difference of Necessity score and Concerns score. ${ }^{38}$ The scoring of NCD ranges from -20 to +20 . The scoring is translated into cost-benefit analysis among the patients' perception towards the benefits (Necessity belief) and cost (Concern) of hypertensive medication. The patient has perception for the benefit of medication outweighs the costs if the difference is positive. Our previous linguistic and validation study has demonstrated Malay language BMQ provided a good internal consistency (Cronbach's alpha $=0.860$ ) among local hypertensive patient. While Self-reported QUM refers to the pattern of medication use and knowledge of hypertension management.

\section{Data Analysis}

SPSS version 16.0 was used to analyse the statistical analyses. The data were tested for normality in order to determine either parametric or non-parametric tests were used accordingly prior statistical tests. Univariate analysis such as Wilcoxon Signed Rank Test (Changes of MALMAS scores), Paired $t$-test (pre/post mean BPs and NCD) and Pearson Chi-square test for independent proportions. Multivariate analyses include Repeated Measures Anova Test and Friedman Test was used accordingly. The level of significance used in all tests was set at 0.05 .

\section{RESULTS}

Out of 56 eligible participants recruited, 45 of them agreed to participate and 11 of the participants were excluded (8 participants were excluded due to serious chronic cardiovascular and kidney diseases with special care needed, 2 participants declined to participate due to time constraint and 1 had not been contacted). 1 participant could not be contacted after the 2-month intervention (Module I and Module II). While another 3 participants lost to follow up prior the final assessment. Figure 1 presents the flow diagram of the study. 


\section{Table 1: Module Contents for the Health Education} Program on Hypertension Syllabus.

\begin{tabular}{|c|c|}
\hline $\begin{array}{l}\text { Module 1: Introduction } \\
\text { of hypertension }\end{array}$ & $\begin{array}{l}\text { - Identify the major risk factors } \\
\text { associated with hypertension } \\
\text { - Identify the signs and symptoms } \\
\text { of hypertension } \\
\text { - Understanding the complications } \\
\text { of hypertension }\end{array}$ \\
\hline $\begin{array}{c}\text { Module 2: } \\
\text { Pharmacological } \\
\text { Management of } \\
\text { hypertension }\end{array}$ & $\begin{array}{l}\text { - Identify classification of } \\
\text { hypertensive medication } \\
\text { To understand function of each } \\
\text { hypertensive medication } \\
\text { To understand the side effects } \\
\text { of each group of hypertensive } \\
\text { medications }\end{array}$ \\
\hline Module 3: QUM & $\begin{array}{l}\text { - To understand the correct way of } \\
\text { consuming medication } \\
\text { To understand the proper } \\
\text { storage of medication }\end{array}$ \\
\hline $\begin{array}{c}\text { Module 4: Non } \\
\text { Pharmacological } \\
\text { Management of } \\
\text { Hypertension - Diet } \\
\text { and Lifestyle changes }\end{array}$ & $\begin{array}{l}\text { - Identify ways to control obesity } \\
\text { To understand healthy lifestyles: } \\
\text { Avoid smoking and more } \\
\text { exercise } \\
\text { - How to handle stress } \\
\text { - } \quad \text { To understand healthy diet }\end{array}$ \\
\hline
\end{tabular}

\section{Demographics Characteristics of Participants at Baseline}

The mean age of the participants was $53.5 \pm 7.2$ years old and mean BP level was 154/90 $\pm 13 / 12 \mathrm{mmHg}$. Majority of the participants were female $(63.4 \%, n=26)$. Malay is the highest ethnic in this study $(56.1 \%)$, followed by Indian (34.1\%) and Chinese (9.8\%). Most of the participants $(36.6 \%)$ had primary school education level. Majority of the participants (68.3\%) earned less than RM 1000 (USD 234) per month. The participants had average duration of hypertension as $6.0 \pm 4.6$ years. The average number of medication taken daily was 2.0 \pm 1.7 pieces. The demographic characteristics of the participants are shown in Table 2.

\section{Outcome Measure: Blood Pressure Level}

At the baseline, the mean SBP was $153.9 \pm 12.7 \mathrm{mmHg}$ and DBP was $90.1 \pm 11.5 \mathrm{mmHg}$. Both SBP $(146.6 \pm$ $11.1 \mathrm{mmHg}, P<0.001)$ and DBP $(87.6 \pm 9.6 \mathrm{mmHg}$, $P=0.002)$ decreased significantly after the 2-months intervention. Moreover, SBP was successfully reduced significantly to $140.1 \pm 10.7 \mathrm{mmHg}(P<0.001)$ after the 4 -months intervention. In contrast, there were no significant changes in DBP $(86.0 \pm 12.2 \mathrm{mmHg}, P=0.352)$ after the 4-months intervention. A one-way repeated measured Analysis of Variance (ANOVA) was conducted to evaluate the null hypothesis that there is no change in participants' SBP and DBP when measured at baseline, 2-months and 4-months intervention $(N=41)$.

\section{Table 2: Demographic Characteristics of the Partici-} pants $(n=41)$.

\begin{tabular}{|c|c|c|c|}
\hline $\begin{array}{l}\text { Demographic } \\
\text { characteristics }\end{array}$ & $n(\%)$ & Mean (SD) & $\begin{array}{c}\text { Median } \\
\text { (IQR) }\end{array}$ \\
\hline Age (years) & & $53.5(7.2)$ & \\
\hline $\begin{array}{l}\text { BP level }(\mathrm{mmHg}) \\
\text { SBP level } \\
\text { DBP level }\end{array}$ & & $\begin{array}{c}153.9(12.7) \\
90.1(11.5)\end{array}$ & \\
\hline $\begin{array}{l}\text { Gender } \\
\text { Male } \\
\text { Female }\end{array}$ & $\begin{array}{l}15(36.6) \\
26(63.4)\end{array}$ & & \\
\hline $\begin{array}{l}\text { Ethnic } \\
\text { Malay } \\
\text { Chinese } \\
\text { Indian }\end{array}$ & $\begin{array}{l}23(56.1) \\
4(9.8) \\
14(34.1)\end{array}$ & & \\
\hline $\begin{array}{l}\text { Education level } \\
\text { No formal education } \\
\text { Primary school } \\
\text { Secondary school } \\
\text { College/ University }\end{array}$ & $\begin{array}{c}10(24.4) \\
15(36.6) \\
13(31.7) \\
3(7.3)\end{array}$ & & \\
\hline 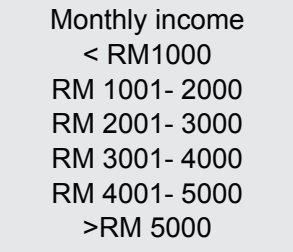 & $\begin{array}{l}28(68.3) \\
5(12.2) \\
4(9.8) \\
2(4.9) \\
1(2.4) \\
1(2.4)\end{array}$ & & \\
\hline $\begin{array}{l}\text { Occupation } \\
\text { Government sector } \\
\text { Private sector } \\
\text { Retired } \\
\text { Unemployed }\end{array}$ & $\begin{array}{c}1(2.4) \\
14(34.1) \\
6(14.6) \\
20(48.8)\end{array}$ & & \\
\hline $\begin{array}{l}\text { Living status } \\
\text { Alone } \\
\text { With family }\end{array}$ & $\begin{array}{c}4(9.8) \\
37(90.2)\end{array}$ & & \\
\hline $\begin{array}{c}\text { Smoking status } \\
\text { Yes } \\
\text { No }\end{array}$ & $\begin{array}{c}7(17.1) \\
34(82.9)\end{array}$ & & \\
\hline $\begin{array}{c}\text { Other co-morbidities } \\
\text { Yes } \\
\text { No }\end{array}$ & $\begin{array}{l}24(58.5) \\
17(41.5)\end{array}$ & & \\
\hline $\begin{array}{c}\text { Duration of } \\
\text { hypertension (years) }\end{array}$ & & & $\begin{array}{c}6.0 \\
(4.6)^{\mathrm{a}}\end{array}$ \\
\hline $\begin{array}{c}\text { Number of } \\
\text { medications taken } \\
\text { daily }\end{array}$ & & & $\begin{array}{c}2.0 \\
(1.7)^{a}\end{array}$ \\
\hline
\end{tabular}

$\mathrm{SD}=$ Standard Deviation; IQR = Interquartile range; a the distribution is skewed to the right

The results of the ANOVA indicated a significant time effects for SBP [Wilks'Lambda $=0.231, F(2,39)=$ 65.01, $\left.P<0.001, \eta^{2}=0.77\right]$ and DBP [Wilks'Lambda $=$ $\left.0.769, F(2,39)=5.85, P=0.006, \eta^{2}=0.23\right]$. Thus, there 


\begin{tabular}{|c|c|c|c|c|c|c|}
\hline Variable & $\begin{array}{l}\text { Baseline } \\
\text { score }\end{array}$ & $\begin{array}{c}\text { Post interventional } \\
\text { score } \\
\text { (2 months) }\end{array}$ & $\begin{array}{c}P \\
\text { Valuea }\end{array}$ & $\begin{array}{c}\text { Post Intervention } \\
\text { score } \\
\text { (4 months) }\end{array}$ & $\begin{array}{c}P \\
\text { value } \beta\end{array}$ & $\begin{array}{c}P \\
\text { valuey }\end{array}$ \\
\hline SBP level (Mean \pm SD) & $153.9(12.7)$ & $\begin{array}{l}146.6 \\
(11.1)\end{array}$ & $<0.001 a$ & $140.1(10.7)$ & $<0.001^{a}$ & $<0.001^{c}$ \\
\hline $\begin{array}{l}\text { DBP level } \\
\text { Mean (SD) }\end{array}$ & $90.1(11.5)$ & $87.6(9.6)$ & $0.002^{a}$ & $86.0(12.2)$ & $0.352^{\mathrm{a}}$ & $0.006^{c}$ \\
\hline $\begin{array}{c}\text { Patient's belief (NCD) } \\
\text { Mean (SD) }\end{array}$ & $4.1(4.2)$ & $6.6(5.4)$ & $0.004^{a}$ & $10.4(3.3)$ & $<0.001^{a}$ & $<0.001^{\circ}$ \\
\hline $\begin{array}{l}\text { Medication adherence } \\
\text { (MALMAS) } \\
\text { Median }\left(25^{\text {th }} \text { and } 75^{\text {th }}\right. \\
\text { percentile) }\end{array}$ & $\begin{array}{c}5.3 \\
(3.6-6.3)\end{array}$ & $\begin{array}{c}6.0 \\
(5.0-7.0)\end{array}$ & $<0.001^{b}$ & $7.0(5.8-7.9)$ & $0.003^{b}$ & $<0.001^{\mathrm{d}}$ \\
\hline
\end{tabular}

${ }^{\alpha}$ Changes from baseline to 2 -months' intervention; ${ }^{\beta}$ Changes from 2 -months' to 4 -months' intervention; ${ }^{\gamma}$ Changes from baseline to 2 -months' intervention and 4-months' intervention;

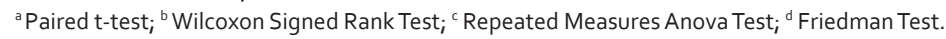

is significant evidence to reject the null hypothesis (Table 3).

\section{Outcome Measure: Beliefs About Medicines (BMQ)}

In terms of patients' Beliefs About Medicines (BMQ) scores, BMQ Specific Necessity was significantly increased from baseline $(15.15 \pm 3.38)$ to 2 -months intervention $(19.51 \pm 2.69, P<0.001)$ and to 4 -months intervention $(21.02 \pm 1.65, P<0.001)$. In addition, BMQ specific Concern was significantly decreased from baseline (15.02 \pm 4.15) to 2 -months intervention $(12.87 \pm 3.87, P=0.016)$ and it was further decreased significantly to $10.61 \pm 2.19(P$ $<0.001)$. Table 3 showed there were significantly increase in NCD from baseline ( $4.1 \pm 4.2)$ to 2 -months intervention $(6.5 \pm 5.4, P=0.004)$ and 4-months intervention $(10.4 \pm$ 3.3, $P<0.001)$.

\section{Outcome measure: Medication Adherence (MALMAS)}

After intervention program, the number of medication adherents increased significantly from baseline $(29.3 \%)$ to 2-months interventions $(58.5 \%, P=0.005)$ and 4-months interventions $(70.7 \%, P<0.001)$ (Table 4). Post intervention, changes in the median Medication Adherence (MALMAS) scores were observed with an improvement of 0.7 points $(P<0.001)$ (from baseline to 2 -months intervention) and 1.0 point $(P=0.003)$ (from 2 -months intervention to 4-months intervention). A non-parametric Friedman test of differences among repeated measures was conducted and rendered a Chi-square value of 34.86 which was significant $(P<0.001)$ (Table 3).

\section{Outcome Measure: QUM}

The number of participants who remembered the name of medication(s) that were currently taking for hyper- tension was marked and statistically significant increased from baseline $(24.4 \%, n=10)$ to 2 -months $(58.5 \%, n=24$, $P=0.002)$ and 4-months intervention $(87.8 \%, n=36$, $P=0.004)$. A significant difference in the knowledge of BP level $(\mathrm{mmHg})$ for a hypertensive patient were also noted between the different time points (baseline to 2-months intervention, $P=0.031$; 2-months to 4 -months intervention, $P<0.001)$. However, in terms of checking the expiry date of your medication(s), there were no significant differences among the different time points $(P>0.05)$.

\section{DISCUSSION}

After the 4 months health education program, this pilot study has demonstrated significant improvement in blood pressure, belief about medicine, medication adherence and QUM can be achieved with community-based pharmacist led education program.

In the present study, the participants experienced significant SBP reduction from baseline to study end point (4-months intervention). The reduction of SBP in the first 2 -months intervention provided with a more pronounced SBP difference compare to the 4-months intervention (7.3 $\mathrm{mmHg}$ vs $6.5 \mathrm{mmHg}$ ) (Table 3). The total of $13.8 \mathrm{mmHg}$ reduction in SBP in this study is consistent with the findings of a Canada study $(13.5 \mathrm{mmHg}) .{ }^{15}$ Two meta-analysis of pharmacist led intervention programs reported lower SBP reduction with $10.7 \mathrm{mmHg}$ and $6.1 \mathrm{mmHg}$ respectively. ${ }^{18,39}$ These could be explained that the average patient age (63 years old) employed in the meta-analysis were older than with the participants in the present study (54 years old). Literature revealed that patient education on chronic disease is more effective with younger patients. ${ }^{40}$ The present study demonstrated an effective community based pharmacist led education program in improving clinical outcomes in hypertensive patients. Literature 


\begin{tabular}{|c|c|c|c|c|c|c|c|}
\hline No & \multicolumn{2}{|l|}{ Item } & $\begin{array}{l}\text { Baseline } \\
\text { score }\end{array}$ & $\begin{array}{c}\text { Post interventional } \\
\text { score } \\
\text { (2 months) }\end{array}$ & $\begin{array}{c}P \\
\text { Value }^{\alpha}\end{array}$ & $\begin{array}{c}\text { Post Intervention } \\
\text { score } \\
\text { (4 months) }\end{array}$ & $\begin{array}{c}P \\
\text { value }^{\beta}\end{array}$ \\
\hline \multirow[t]{2}{*}{ i } & \multirow{2}{*}{$\begin{array}{c}\text { Medication adherence }{ }^{\pi} \\
\text { (MALMAS) } \\
n(\%)\end{array}$} & Yes & $12(29.3)$ & $24(58.5)$ & \multirow[t]{2}{*}{$0.005^{\mathrm{a}}$} & $29(70.7)$ & \multirow{2}{*}{$<0.001^{a}$} \\
\hline & & No & $29(70.7)$ & $17(41.5)$ & & $12(29.3)$ & \\
\hline \multirow[t]{2}{*}{ ii } & \multirow{2}{*}{$\begin{array}{c}\text { Do you remember the } \\
\text { name of medication(s) that are } \\
\text { currently } \\
\text { taking for } \\
\text { hypertension? } \\
n(\%)\end{array}$} & Yes & $10(24.4)$ & $24(58.5)$ & \multirow[t]{2}{*}{$0.002^{a}$} & $36(87.8)$ & \multirow[t]{2}{*}{$0.004^{a}$} \\
\hline & & No & $31(75.6)$ & $17(41.5)$ & & $5(12.2)$ & \\
\hline \multirow[t]{2}{*}{ iii } & \multirow{2}{*}{$\begin{array}{c}\text { Do you always check } \\
\text { the expiry date of your } \\
\text { medication(s)? } \\
n(\%)\end{array}$} & Yes & $19(46.3)$ & $35(85.4)$ & \multirow[t]{2}{*}{$0.120^{a}$} & $40(97.6)$ & \multirow{2}{*}{$0.684^{a}$} \\
\hline & & No & $22(53.7)$ & $6(14.6)$ & & $1(2.4)$ & \\
\hline \multirow[t]{2}{*}{ iv } & \multirow{2}{*}{$\begin{array}{l}\text { Have you ever shared your } \\
\text { antihypertensive medicine(s) } \\
\text { with others? }\end{array}$} & Yes & $6(14.6)$ & $2(4.9)$ & \multirow[t]{2}{*}{$0.560^{\mathrm{a}}$} & $2(4.9)$ & \multirow[t]{2}{*}{$0.750^{a}$} \\
\hline & & No & $35(85.4)$ & 39 (95.1) & & 39 (95.1) & \\
\hline v & 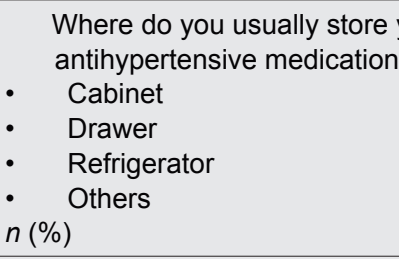 & & $\begin{array}{l}25(61.0) \\
7(17.1) \\
5(12.2) \\
4(9.8)\end{array}$ & $\begin{aligned} 32 & (78.0) \\
3 & (7.3) \\
1 & (2.4) \\
5 & (12.1)\end{aligned}$ & $<0.001^{a}$ & $\begin{aligned} 36 & (87.8) \\
2 & (4.9) \\
1 & (2.4) \\
2 & (4.9)\end{aligned}$ & $<0.001^{a}$ \\
\hline vi & \multicolumn{2}{|c|}{$\begin{array}{l}\text { What is the targeted BP (BP) level } \\
\text { (mmHg) for a hypertensive patient } \\
\text { without diabetes and cardiovascular } \\
\quad<100 / 80 \\
\quad<140 / 90 \\
\text { - } \quad<160 / 100 \\
\text { I do not know } \\
n(\%)\end{array}$} & $\begin{array}{l}6(14.6) \\
9(22.0) \\
8(19.5) \\
18(43.9)\end{array}$ & $\begin{array}{c}5(12.2) \\
32(78.0) \\
1(2.4) \\
3(7.3)\end{array}$ & $0.031^{a}$ & $\begin{array}{c}1(2.4) \\
39(95.1) \\
0 \\
1(2.4)\end{array}$ & $<0.001^{a}$ \\
\hline
\end{tabular}

"Level of adherence refers to the Malaysian Medication Adherence Scale (MALMAS) score of 8; adherence refers to high score of MALMAS (6-8) and non-adherence refers low MALMAS score of $<6$.

${ }^{\alpha}$ Changes from baseline to 2-months' intervention; ${ }^{\beta}$ Changes from 2-months' to 4 -months' intervention; ${ }^{\text {a }}$ Pearson Chi-square test for independence.

have shown that a reduction of $5 \mathrm{mmHg}$ of SBP could reduce chances of mortality due to stroke and cardiovascular heart disease by $14 \%$ and $7 \%$ respectively. ${ }^{7,8}$

Previous studies reported that patient education program on disease-related knowledge may enhance patients' understanding towards their health problem and the beneficial of medical therapy. ${ }^{41,42}$ Similarly, the outcome of this study confirmed this finding. The health education program in this study has significantly increased the participants' belief and attitude towards the beneficial of medication. These observations highlighted the improvement belief towards necessity of medication and reducing concern about medication side effect and toxicity. Throughout the NCD value after completion of the interactive education intervention, participants in this study have higher perception of the benefit of medication outweigh the costs (Concern) which is in line with previous studies. ${ }^{13,43}$

The balancing between the perceived beneficial and harmful of a medication has greatly correlated with patient's choice in taking medication. Taking this into consideration, the findings of this study reported a marked increase in medication adherence throughout the education program. These findings are similar to previous literature demonstrating the impacts of pharmacist led education program to improve medication adherence. ${ }^{15,44,45} \mathrm{~A}$ meta-analysis of randomised control trials conducted by Cheema et al. reported that 6 out of 7 studies had significantly increased in medication adherence from $56 \%$ to $68 \%$ in the intervention groups compare to control groups (Odds ratio 12.1, 95\% CI 4.2-34.6; $P<0.001) .{ }^{18}$ Medication adherence could be 


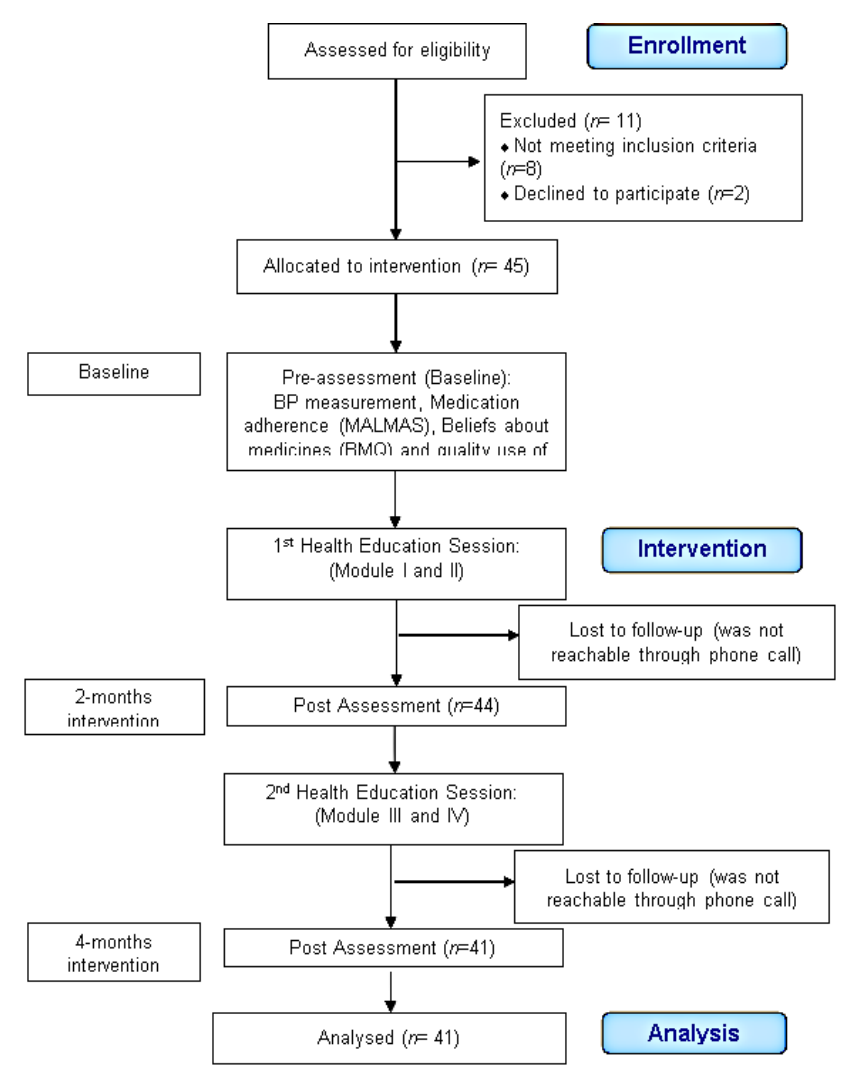

Figure 1: Flowchart of Health Education Program.

improved by understanding to the nature of the disease and the rationale of the medication. ${ }^{46}$ Medicationrelated problems, such as errors of improper dose and compliance, been prevented throughout the pharmacist led interactive education program. Despite all the doubts and myths were answered individually, further systematic therapeutic planning were developed between pharmacist and patients in the education program.

QUM education programs are effective in increasing patients' knowledge about their illnesses, modifying their beliefs towards medication use, alter the medication taking behaviour and thus improve health related outcomes. ${ }^{15,47}$ As medicines experts in primary care, pharmacists are in an ideal position to address adherence and persistence issues in people with hypertension in community level. ${ }^{48,49}$ Pharmacists are uniquely positioned in the healthcare system to undertake a role in cardiovascular medication management in community level..$^{50}$ The present findings demonstrated that the number of participants who remembered the name of medication(s) that are currently taking for hypertension were significantly increased after the education program. Instead of remembering the brand name of medication, the ability of remembering active ingredient name of medication is crucially important in order to prevent medication error for example double dose of same medication. In Malaysia, the branding of medication supplied by government hospital might change from time to time after completion of contract with pharmaceutical companies. Therefore, there will be high possibility for the patients to receive different brands of medication (with same active ingredient) from hospital or community pharmacies. Collaboration between pharmacist and patient can enable QUM.

\section{Limitation}

This study was carried out at specific region and short follow-up period, thus it may not be generalizable to other area settings in Malaysia. However, mix ethnic of participants were recruited in this study to reflect the actual society of Malaysia. A future larger scale with longer follow-up period which involve other states in the country could address this limitation to provide more robust data of the study. Another limitation in this study is that the trial was not blinded among the participants. However, blinding method is unlikely to apply to participants in such health education program.

\section{CONCLUSION}

The findings from this study demonstrated that pharmacist led health education program has significantly desirable effects on improvement of blood pressure, better beliefs about medicine, improvement of medication adherence and QUM. It is feasible for pharmacists to extend their services by continually provide health education program to hypertensive patients at community level. Taking consideration of the positive outcomes of this study and the increasing number of pharmacists in the country, national health policy maker and professional organisation could enact policies or regulation to place the final year pharmacy students and provisional register pharmacists in the public health education program at the community level.

\section{ACKNOWLEDGEMENT}

The author would like to thank Penang Family Health Development Association (FHDA) Non Government Association (NGO) member Ms. Jayaletchamee and Ms. Yoke Peng. Besides, the authors also want to thank Ms. Vijaya, a committee member of Flat Desa Wawasan and Diploma in Pharmacy students from KPJ International College who assisted in this program. Lastly appreciation would like to extend to the participants who took part in this study.

\section{CONFLICT OF INTEREST}

The authors declare no conflict of interest. 


\section{ABBREVIATIONS}

BP: Blood Pressure; JNC 7: Joint National Committee 7; mmHg: Millimeters of Mercury; SBP: Systolic Blood Pressure; DBP: Diastolic Blood Pressure; QUM: Quality Use of Medicine; MALMAS: Malaysian Medication Adherence Assessment; BMQ: Beliefs about Medicines Questionnaire; NCD: Necessity-Concerns differential; ANOVA: Analysis of Variance; FHDA: Family Health Development Association; NGO: Non Government Organization.

\section{REFERENCES}

1. World Health Organization. World Health Report: Reducing risks, promoting healthy life. 2002. http://www.who.int/whr/2002/.

2. World Health Organization. A Global Brief on Hypertension: Silent Killer, Global Public Health Crisis. 2013. http://apps.who.int/iris/bitstream/10665/79059/1/ WHO_DCO_WHD_2013.2_eng.pdf?ua=1.

3. Chobanian AV, Bakris GL, Black HR, et al. The seventh report of the joint national committee on prevention, detection, evaluation and treatment of high blood pressure: the JNC 7 report. JAMA. 2003;289(19):2560-71.

4. Ministry of Health Malaysia. National Health and Morbidity Survey 2015. 2015;2.

5. Rampal L, Rampal S, Azhar M, Rahman AR. Prevalence, awareness, treatment and control of hypertension in Malaysia: A national study of 16,440 subjects. Public Health. 2008;122(1):11-8.

6. World Health Organization. Causes of Death 2008: Data Sources and Methods. 2011. http://www.who.int/healthinfo/global_burden_disease/ cod_2008_sources_methods.pdf.

7. Whelton PK, He J, Appel LJ, et al. Primary prevention of hypertension: Clinical and public health advisory from The National High Blood Pressure Education Program. JAMA. 2002;288(15):1882-8.

8. Stamler R. Implications of the INTERSALT study. Hypertension. 1991;17(1 Suppl):I16.

9. Ambaw AD, Alemie GA, Mengesha ZB. Adherence to antihypertensive treatment and associated factors among patients on follow up at University of Gondar Hospital, Northwest Ethiopia. BMC Public Health. 2012;12(1):282.

10. Sabaté E. Adherence to long-term therapies: evidence for action. World Health Organization. 2003.

11. Ramli A, Ahmad NS, Paraidathathu T. Medication adherence among hypertensive patients of primary health clinics in Malaysia. Patient Preference and Adherence. 2012;6:613-22.

12. Tan CS, Hassali MA, Neoh CF, Saleem F. A qualitative exploration of hypertensive patients' perception towards quality use of medication and hypertension management at the community level. Pharmacy Practice. 2017;15(4):1074.

13. Lu CH, Tang ST, Lei YX, et al. Community-based interventions in hypertensive patients: A comparison of three health education strategies. BMC Public Health. 2015;15(1):33

14. Weinman J. Providing written information for patients: Psychological considerations. Journal of the Royal Society of Medicine. 1990;83(5):303.

15. Ontario Pharmacists Association and Green Shield Canada. Impact of Community Pharmacist Interventions in Hypertension Management on Patient Outcomes: A Randomized Controlled Trial. 2014. https://www. opatoday.com/Media/Default/Reports/Hypertension $\% 20$ Study $\% 20-\% 20$ Final\%20Report\%20(January\%208\%202014).pdf.

16. Bajorek B, Lemay KS, Magin P, Roberts C, Krass I, Armour CL. Implementation and evaluation of a pharmacist-led hypertension management service in primary care: outcomes and methodological challenges. Pharmacy Practice. 2016;14(2):0.

17. Hedegaard $U$, Kjeldsen LJ, Pottegård A, et al. Improving medication adherence in patients with hypertension: A randomized trial. The American Journal of Medicine. 2015;128(12):1351-61.
18. Cheema $E$, Sutcliffe $P$, Singer $D R$. The impact of interventions by pharmacists in community pharmacies on control of hypertension: A systematic review and meta-analysis of randomized controlled trials. British Journal of Clinical Pharmacology. 2014;78(6):1238-47.

19. Castelino RL, Bajorek BV, Chen TF. Retrospective evaluation of home medicines review by pharmacists in older Australian patients using the medication appropriateness index. Annals of Pharmacotherapy. 2010;44(12):1922-9.

20. Bajorek BV, Lemay KS, Magin PJ, Roberts C, Krass I, Armour CL. Preparing pharmacists to deliver a targeted service in hypertension management: Evaluation of an interprofessional training program. BMC Medical Education. 2015;15(1):157.

21. Krass I, Hebing $\mathrm{R}$, Mitchell $\mathrm{B}$, et al. Diabetes management in an Australian primary care population. Journal of Clinical Pharmacy and Therapeutics. 2011;36(6):664-72.

22. Ling $Y$, Fang Z, Shen W, Zhang $Y$, Zhao $X$. The effectiveness evaluation on the Pengpu Community Health Center implementation of the health education and health promotion for community hypertension patients. Chinese Primary Health Care. 2004;18(9):37-9.

23. Beigi MAB, Zibaeenezhad MJ, Aghasadeghi K, Jokar A, Shekarforoush $\mathrm{S}$, Khazraei $\mathrm{H}$. The effect of educational programs on hypertension management. International Cardiovascular Research Journal. 2014;8(3):94.

24. Garrity T, Garrity A. The nature and efficacy of intervention studies in the National High Blood Pressure Education Research Program: Journal of hypertension. Supplement: Official Journal of the International Society of Hypertension. 1985;3(1):S91-5.

25. Olubodun JOB, Falase AO, Cole TO. Drug compliance in hypertensive Nigerians with and without heart failure. International Journal of Cardiology. 1990;27(2):229-34.

26. Lambert A, Mpoy M, Vandeleene B, Ketelslegers JM. Treatment of hypertension in diabetic patients. The American Journal of Medicine. 1989;87(3):S30-3.

27. Collins R, MacMahon S. Blood pressure, antihypertensive drug treatment and the risks of stroke and of coronary heart disease. British Medical Bulletin. 1994;50(2):272-98.

28. Gueyffier F, Bulpitt C, Boissel JP, et al. Antihypertensive drugs in very old people: A subgroup meta-analysis of randomised controlled trials. The Lancet. 1999;353(9155):793-6.

29. Prospective Studies Collaboration. Age-specific relevance of usual blood pressure to vascular mortality: A meta-analysis of individual data for one million adults in 61 prospective studies. The Lancet. 2002;360(9349):190313.

30. Dawson B, Trapp RG. Basic and Clinical Biostatistics: Finding the Sample Size for Studies with One Mean: Lange Medical Books/McGraw-Hill. 2004.

31. Robinson JD, Segal R, Lopez LM, Doty RE. Impact of a pharmaceutical care intervention on blood pressure control in a chain pharmacy practice. Annals of Pharmacotherapy. 2010;44(1):88-96.

32. Chabot I, Moisan J, Grégoire JP, Milot A. Pharmacist intervention program for control of hypertension. Annals of Pharmacotherapy. 2003;37(9):1186-93.

33. Zillich AJ, Sutherland JM, Kumbera PA, Carter BL. Hypertension outcomes through blood pressure monitoring and evaluation by pharmacists. Journal of General Internal Medicine. 2005;20(12):1091-6.

34. Chua SS, Lai P, Tan CH, Chan SP, Chung W, Morisky DE. The development and validation of the Malaysian Medication Adherence Scale (MALMAS) among patients with 2 type diabetes in Malaysia. Int $\mathrm{J}$ Pharm Pharm Sci. 2013;5(3):790-4

35. Chung WW, Chua SS, Lai PSM, Morisky DE. The Malaysian Medication Adherence Scale: Concurrent validity using a clinical measure among people with Type 2 diabetes in Malaysia. PloS One. 2015;10(4):e0124275.

36. Krousel-Wood M, Islam T, Webber LS, Re R, Morisky DE, Muntner P. New medication adherence scale versus pharmacy fill rates in hypertensive seniors. The American Journal of Managed Care. 2009;15(1):59.

37. Horne R, Weinman J, Hankins M. The beliefs about medicines questionnaire: the development and evaluation of a new method for assessing the cognitive representation of medication. Psychology and Health. 1999;14(1):1-24.

38. Horne R, Weinman J. Patients' beliefs about prescribed medicines and their role in adherence to treatment in chronic physical illness. Journal of Psychosomatic Research. 1999;47(6):555-67. 
39. Machado M, Bajcar J, Guzzo GC, Einarson TR. Hypertenion: Sensitivity of Patient Outcomes to Pharmacist Interventions. Part II: Systematic Review and Meta-Analysis in Hypertension Management. Annals of Pharmacotherapy. 2007;41(11):1770-81.

40. Brown SA. Meta-analysis of diabetes patient education research: Variations in intervention effects across studies. Research in Nursing and Health. 1992;15(6):409-19.

41. Kruger HS, Gerber J. Health beliefs and compliance of black South African outpatients with antihypertensive medication. Journal of Social and Administrative Pharmacy. 1998;15:201-9.

42. Saounatsou M, Patsi O, Fasoi G, et al. The influence of the hypertensive patient's education in compliance with their medication. Public Health Nursing. 2001;18(6):436-42.

43. Ali M, Schifano $F$, Robinson $P$, et al. Impact of community pharmacy diabetes monitoring and education programme on diabetes management: $\mathrm{A}$ randomized controlled study. Diabetic Medicine. 2012;29(9):e326-33.

44. Erku DA, Ayele AA, Mekuria AB, Belachew SA, Hailemeskel B, Tegegn HG. The impact of pharmacist-led medication therapy management on medication adherence in patients with type 2 diabetes mellitus: A randomized controlled study. Pharmacy Practice. 2017;15(3).
45. Marfo AFA, Owusu-Daaku FT. Exploring the extended role of the community pharmacist in improving blood pressure control among hypertensive patients in a developing setting. Journal of Pharmaceutical Policy and Practice. 2017;10(1):39.

46. Bond W, Hussar D. Detection methods and strategies for improving medication compliance. American Journal of Health-System Pharmacy. 1991;48(9):1978-88.

47. Mohamad AH, Fahad S, Mohd DM, et al. A National Survey on the Use of Medicines by malaysian consumers. 2015

48. Duerden M, Millson D, Avery A, Smart S. The quality of GP prescribing. An inquiry into the quality of general practice in England. London. 2011. https:// www.kingsfund.org.uk/sites/default/files/field/field_document/quality-gpprescribing-gp-inquiry-research-paper-mar11.pdf.

49. Houle SK, Chuck AW, McAlister FA, Tsuyuki RT. Effect of a PharmacistManaged Hypertension Program on Health System Costs: An Evaluation of the Study of Cardiovascular Risk Intervention by Pharmacists-Hypertension. Pharmacotherapy: The Journal of Human Pharmacology and Drug Therapy. 2012;32(6):527-37.

50. Szkiladz A, Carey K, Ackerbauer K, Heelon M, Friderici J, Kopcza K. Impact of pharmacy student and resident-led discharge counseling on heart failure patients. Journal of Pharmacy Practice. 2013:26(6):574-9.

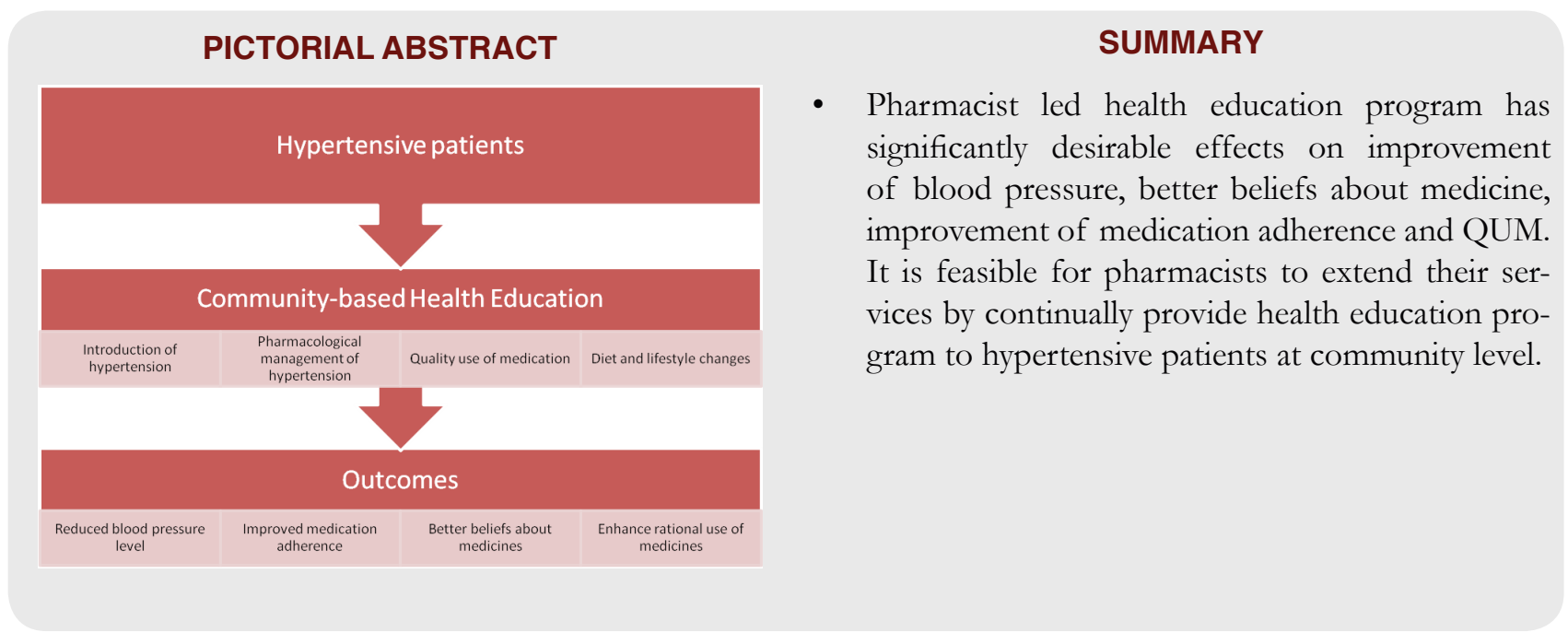

Cite this article: Siang TC, Hassali MAA, Fen NC. The Role of Pharmacist in Managing Hypertension in the Community: Findings from a Community Based Study. Indian J of Pharmaceutical Education and Research. 2019;53(3):553-61. 